\title{
Primary Rectal Amelanotic Malignant Melanoma: A Rare Case Report
}

Rubab Nafees ${ }^{1}$, Hina Khan ${ }^{2}$, Shahrukh Ahmed ${ }^{1}$, Khursheed Ahmed Samo ${ }^{2}$, Amjad Siraj Memon ${ }^{2}$

1. Surgery, Dr. Ruth K. M. Pfau Civil Hospital Karachi, Karachi, PAK 2. Surgery, Dow University of Health Sciences, Civil Hospital Karachi, Karachi, PAK

Corresponding author: Hina Khan, hina.khan@duhs.edu.pk

\begin{abstract}
Malignant melanoma of the rectum comprises $0.5 \%-4 \%$ of all anorectal cancers. Malignant melanoma of the rectum is exceptionally a rare disease. It commonly affects the fifth or sixth decade, with nonspecific symptoms such as rectal bleeding or anal pain. After skin and retina, anorectum is the third common site for malignant melanoma. Proper diagnosis is difficult in the majority of cases due to lack of pigmentation and amelanotic histological appearance. Prognosis is very poor with a median survival of 24 months and fiveyear survival of $10 \%-15 \%$. Anorectal malignant melanomas disseminate along the submucosal planes, therefore complete resection at the time of diagnosis is usually not possible.
\end{abstract}

Categories: General Surgery

Keywords: colorectal cancer, malignant melanoma, amelanotic, anorectal melanoma

\section{Introduction}

Malignant melanoma of the rectum is an uncommon disease, which constitutes $0.5 \%-4 \%$ of all anorectal malignancies and less than $1 \%$ of all melanomas [1-3]. It usually produces local symptoms in the fifth or sixth decade of life [1]. After skin and retina, anorectum is the third common site for malignant melanoma. Patients often present with nonspecific complaints such as rectal bleeding or anal pain $[2,3]$. It affects the Caucasian race commonly. A prompt diagnosis is more difficult as $80 \%$ of lesions lack pigmentation and up to $20 \%$ of tumours are histologically amelanotic $[4,5]$. Human melanoma black-45 (HMB-45), soluble $100 \%$ (S-100), and melanoma-associated protein A (Melan A) are immunohistochemical stains required for the diagnosis. Prognosis is dismal with a median survival of 24 months and five-year survival of $10 \%-15 \%[1,6]$. Although surgery is the mainstay of treatment, wide local excision and abdominoperineal resections are the options according to the stage of the disease, but presently, there is no consensus on which surgical approach is favorable [3]. It is resistant to radiotherapy and poorly responsive to chemotherapy as well. Anorectal malignant melanomas spread along submucosal planes, therefore, complete resection is impossible at the time of diagnosis, therefore, almost all patients die because of metastases $[7,8]$.

Received 04/29/2020 Review began 05/03/2020 Review ended 05/08/2020 Published 05/14/2020

\section{() Copyright 2020}

Nafees et al. This is an open access article distributed under the terms of the Creative Commons Attribution License CC-BY 4.0., which permits unrestricted use, distribution, and reproduction in any medium, provided the original author and source are credited.

\section{Case Presentation}

A 69-year-old male, with no known comorbidities presented with complains of tenesmus and bleeding per rectum for the last four months. There was no documented weight loss or fever. On digital rectal examination, an irregular thickening of the posterior anorectal wall was noted, starting from the anal verge at 6 o'clock position, and extending upwards with an upper limit not reachable; the anterior anorectal wall was normal. The finger was blood stained. The rest of the systemic examination was unremarkable.

Colonoscopy showed eccentric, ulcerated, friable growth in the rectum starting from the anal verge extending up to $16 \mathrm{~cm}$. There was no luminal narrowing. A biopsy was taken.

CT scan of the chest abdomen pelvis (CAP) showed large polypoidal mass involving proximal and distal rectum, laterally infiltrating the right levator ani muscle, and superiorly reaching up to S2 vertebra, sparing the sigmoid colon. There was significant perirectal fat stranding with lymphadenopathy. No pleural or pulmonary metastasis.

MRI pelvis showed irregular, circumferential, polypoidal abnormal intensity mass lesion involving the anorectal canal. The mass extended from the anal verge, proximally till the distal sigmoid colon. The maximum craniocaudal length of mass measured $15.0 \mathrm{~cm}$, transverse dimension measured $5.2 \mathrm{~cm}$, maximum single wall thickness measured $4.4 \mathrm{~cm}$. Marked perirectal fat stranding was seen extending posteriorly up to the presacral space. Bilateral levator ani muscles were involved. Anteriorly, there was a loss of fat planes with the prostate. There were enlarged perirectal lymph nodes; the largest one measured $1.5 \times 1.1 \mathrm{~cm}$.

carcinoembryonic antigen (CEA) level was 1.7. Histopathology report showed largely necrotic tissue; few atypical viable cells were present which were positive for S-100 and melanocyte marker HMB-45. A possibility of malignant melanoma (amelanotic) was raised. 


\section{Cureus}

Oncology opinion was taken and the patient was planned for abdominoperineal excision of rectum (APER). Operative findings revealed the tumor involving anorectum up to the distal sigmoid colon. Tumour was adherent to the prostate. No liver or peritoneal metastasis was found. Figure 1 shows the postoperative specimen. Postoperative recovery was uneventful and the patient was discharged home.

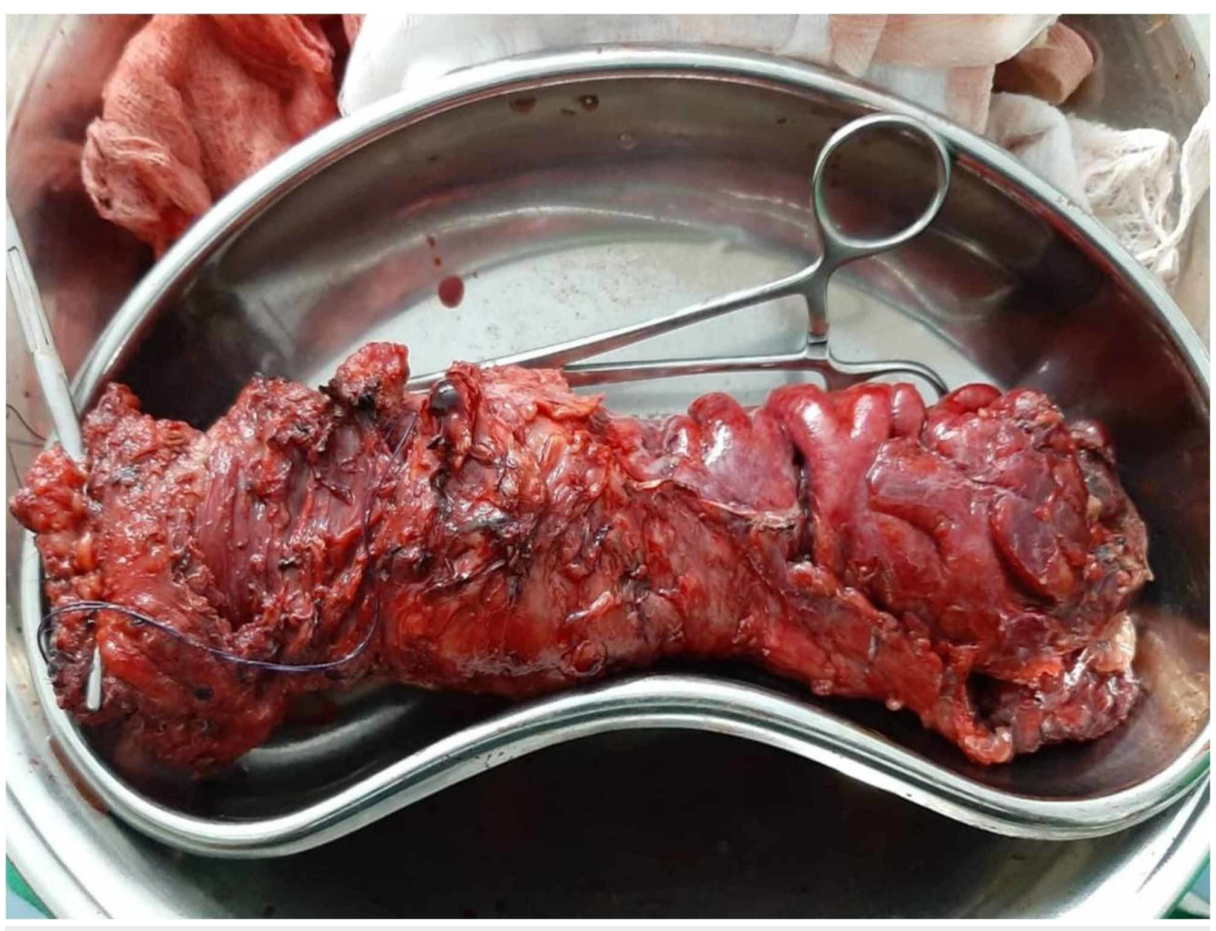

FIGURE 1: Postoperative specimen of anorectal malignant melanoma

Histopathology of the specimen showed tumour infiltrating into the muscularis propria and adipose tissue. The size was $8 \times 7 \times 6 \mathrm{~cm}$, the thickness was $6 \mathrm{~cm}$, mucosal ulceration was present, both resection margins were tumour free; a total of 17 lymph nodes were recovered out of which two were involved by the tumour, and an extra nodal extension was present. Features were consistent with malignant melanoma.

After six months, the patient presented with complaints of nodular swelling over the perineal scar tissue. Examination under anesthesia was done which showed a $3 \times 3 \mathrm{~cm}$ lump at the perineal scar site. Wide local excision was done and the sample was sent for histopathology, which showed features of recurrent malignant melanoma; the size of the lesion was $2.5 \times 2.5 \times 2.2 \mathrm{~cm}$, the closest peripheral margin was $0.4 \mathrm{~cm}$ away, and the deep margin was $0.9 \mathrm{~cm}$ away. CT scan was unremarkable for distant disease. The patient died seven months after the resection due to metastasis.

\section{Discussion}

Melanocytes are derived from the embryological neural crest and migrate to primarily the skin and other locations. Therefore, cutaneous melanomas account for more than $90 \%$ of all melanomas, $5 \%$ retinal melanoma, $2 \%$ melanoma of unknown origin, and $1 \%$ mucosal melanoma [2]. Signs of symptoms are less common in amelanotic malignant melanoma (AMM). Patients who are diagnosed with AMM, already have loco regional metastasis [8]. Lung, liver, brain, bone, and breast are the common sites for distant metastasis [9].

A sigmoido-colonoscopy and endoscopic endorectal ultrasound may be considered to evaluate and diagnose the disease status along with CT scan and MRI pelvis [7].

Immunohistochemical analysis is the cornerstone for the diagnosis of AMM. Anti-S-100 protein is a commonly used stain for AMM and it is highly sensitive for melanocytic differentiation. Other stains are HMB-45, vimentin, and Melan A for the diagnosis of malignant melanoma. In our case, S-100 and melanocyte marker HMB- 45 melanin was a diagnostic marker.

Surgery in combination with adjuvant immunotherapy, like interferon, was reported to be a choice of treatment for amelanotic anorectal melanoma if the tumour is localized [10]. Bullard et al. reported that AMM recurrence is not associated with the initial surgical procedure [11]. In our case, we performed abdominoperineal resection. Local excision is preferred by some surgeons, as abdominoperineal resection 
has a worse prognosis postoperatively [12]. Chemotherapy and radiotherapy have a limited role [13]. Dacarbazine shows a 20\% partial response in four to six months [7]. Japan has shown success in immunotherapy recently by using nivolumab (Opdivo), an antibody to programmed death (PD-1) for controlling metastasis [14]. Our patient died after six months of surgery due to distant metastasis like the other case in the literature $[15,16]$.

\section{Conclusions}

Malignant melanoma of the rectum is extremely rare, highly aggressive, and difficult to diagnose. Although surgery remains the cornerstone of treatment, the exact procedure remains controversial. The role of adjuvant therapies is minimal. Survival can be prolonged only by early diagnosis.

\section{Additional Information \\ Disclosures}

Human subjects: Consent was obtained by all participants in this study. Conflicts of interest: In compliance with the ICMJE uniform disclosure form, all authors declare the following: Payment/services info: All authors have declared that no financial support was received from any organization for the submitted work. Financial relationships: All authors have declared that they have no financial relationships at present or within the previous three years with any organizations that might have an interest in the submitted work. Other relationships: All authors have declared that there are no other relationships or activities that could appear to have influenced the submitted work.

\section{References}

1. van Schaik PM, Ernst MF, Meijer HA, Bosscha K: Melanoma of the rectum: a rare entity . World J Gastroenterol. 2008, 14:1633-5. 10.3748/wig.14.1633

2. Singer M, Mutch MG: Anal melanoma. Clin Colon Rectal Surg. 2006, 19:78-87. 10.1055/s-2006-942348

3. Row D, Weiser MR: Anorectal melanoma. Clin Colon Rectal Surg. 2009, 22:120-6. 10.1055/s-0029-1223844

4. Slingluff CL Jr, Vollmer RT, Seigler HF: Anorectal melanoma: clinical characteristics and results of surgical management in twenty-four patients. Surgery. 1990, 107:1-9.

5. Morson BC, Volkstadt H: Malignant melanoma of the anal canal . J Clin Pathol. 1963, 16:126-32. 10.1136/jcp.16.2.126

6. Liptrot S, Semeraro D, Ferguson A, Hurst N: Malignant melanoma of the rectum: a case report . J Med Case Rep. 2009, 3:9318. 10.1186/1752-1947-3-9318

7. Stefanou A, Nalamati SP: Anorectal melanoma. Clin Colon Rectal Surg. 2011, 24:171-6. 10.1055/s-00311286001

8. Maqbool A, Lintner R, Bokhari A, Habib T, Rahman I, Rao BK: Anorectal melanoma--3 case reports and a review of the literature. Cutis. 2004, 73:409-13.

9. Cagir B, Whiteford MH, Topham A, Rakinic J, Fry RD: Changing epidemiology of anorectal melanoma. Dis Colon Rectum. 1999, 1203-8. 10.1007/BF02238576

10. Kim KW, Ha HK, Kim AY, et al.: Primary malignant melanoma of the rectum: CT findings in eight patients Radiology. 2004, 232:181-6. 10.1148/radiol.2321030909

11. Bullard KM, Tuttle TM, Rothenberger DA, Madoff RD, Baxter NN, Finne CO, Spencer MP: Surgical therapy for anorectal melanoma. J Am Coll Surg. 2003, 196:206-211. 10.1016/S1072-7515(02)01538-7

12. Glowka TR, Keyver-Paik MD, Thiesler T, Landsberg J, Kalff JC, Pantelis D: Anorectal malignant melanoma: treatment recommendations [Article in German]. Chirurg. 2016, 87:768-774. 10.1007/s00104-016-0242-x

13. Malik A, Hull TL, Milsom J: Long-term survivor of anorectal melanoma: report of a case . Dis Colon Rectum. 2002, 1412-1417. 10.1007/s10350-004-6435-2

14. Tokuhara K, Nakatani K, Tanimura H, Yoshioka K, Kiyohara T, Kon M: A first reported case of metastatic anorectal amelanotic melanoma with a marked response to anti-PD-1 antibody nivolumab: a case report. Int J Surg Case Rep. 2017, 31:188-92. 10.1016/j.ijscr.2017.01.028

15. Carcoforo P, Raiji MT, Palini GM, et al.: Primary anorectal melanoma: an update. J Cancer. 2012, 3:449-53. $10.7150 /$ jca. 5187

16. Kohli S, Narang S, Singhal A, Kumar V, Kaur O, Chandoke R: Malignant melanoma of the rectum . J Clin Imaging Sci. 2014, 4:4. 10.4103/2156-7514.126031 